\title{
Fiscaoeconomia
}

E-ISSN: 2564-7504

2022, Volume 6, Issue 1, 99-117

https://dergipark.org.tr/tr/pub/fsecon

\section{BRICS Ülkelerinin Hizmet Ticaretinde Açıklanmış Karşılaştırmalı Üstünlükleri}

\section{Revealed Comparative Advantages in the Services Trade of BRICS Countries}

\section{Yasemin DUMRUL ${ }^{1}$, Zerrin KILIÇARSLAN ${ }^{2}$}

Öz Gelişmişlik düzeyi ne olursa olsun ülkeler için ekonomik yapının değişmesinde, ekonomik büyümenin sağlanmasında, işsizliğin azalmasında ve ihracatın artmasında hizmetler sektörü önemli bir yere sahiptir. Bu çalışmada, 2016-2020 dönemi için Açıklanmış Karşılaştırmalı Üstünlük (RCA) endeksi kullanılarak, BRICS ülke grubu ile grupta yer alan her bir ülke için 12 hizmet alt sektöründe rekabet gücü incelenmiştir. Çalışma sonucunda BRICS ülkelerinin inşaat hizmetleri, telekomünikasyon, bilgisayar ve bilişim hizmetleri ve diğer ticari hizmetlerde dünya karşısında karşılaştırmalı üstünlüğe sahip olduğu tespit edilmiştir. BRICS grubundaki ülkeler ayrı değerlendirildiğinde ise Çin başkalarına ait fiziksel girdiler üzerine imalat ve inşaat hizmetlerinde, Rusya ise inşaat hizmetinde güçlü karşılaştırmalı üstünlüğe sahiptir. Bununla birlikte Hindistan, Brezilya ve Güney Afrika için güçlü karşılaştırmalı üstünlüğe sahip olunan hizmet alt sektörü bulunmamaktadır.

Jel Kodları: F14, N90, 011.

Anahtar Kelimeler: Açıklanmış Karşılaştırmalı Üstünlük Endeksi, Hizmet Sektörü, Rekabet Gücü, BRICS ülkeleri.

\begin{abstract}
Regardless of the level of development, the services sector has an important place in changing the economic structure, ensuring economic growth, decreasing unemployment and increasing exports for countries. In this study, competitiveness in 12 service sub-sectors for the BRICS country group and each country in the group was examined by using the Revealed Comparative Advantage (RCA) index for the period 2016-2020. As a result of the study, it has been determined that BRICS countries have a comparative advantage against the world in construction services, telecommunications, computer and information services and other business services. When the countries in the BRICS group are evaluated separately, China has a strong comparative advantage in manufacturing services on physical inputs owned by others, and Russia in construction services. However, there is no service sub-sector with strong comparative advantage for India, Brazil and South Africa.
\end{abstract}

Jel Codes: F14, N90, 011.

Keywords: Revealed Comparative Advantage Index, Service Sector, Competitiveness, BRICS countries.

\footnotetext{
${ }^{1}$ Doç. Dr., Kayseri Üniversitesi, Develi Hüseyin Şahin MYO, ydumrul@erciyes.edu.tr, ORCID: 0000-0001-59612931

${ }^{2}$ Doç. Dr., Kayseri Üniversitesi, Teknik Bilimler MYO, zkaan@erciyes.edu.tr, ORCID: 0000-0002-0905-3067
}

Citation/Atıf: Dumrul, Y. \& Kılıçarslan, Z. (2022). BRICS Ülkelerinin Hizmet Ticaretinde Açıklanmış Karşılaştırmalı Üstünlükleri. Fiscaoeconomia, 6(1), 99-117. Doi: 10.25295/fsecon.1034136 
Dumrul, Y. \& Kılıçarslan, Z. (2022). BRICS Ülkelerinin Hizmet Ticaretinde Açıklanmış Karşılaştırmalı Üstünlükleri. Fiscaoeconomia, 6(1), 99-117. Doi: 10.25295/fsecon.1034136

\section{Giriş}

Hem gelişmiş hem de gelişmekte olan ülkelerdeki ekonomik dönüşüm ve yapısal değişimde kilit bir faktör olan hizmetler sektörü, gelir artışı, verimlilik, istihdam, yatırım ve ticaret için fırsatlar sunarak ülkelerin büyüme ve gelişmesinde gittikçe daha önemli bir rol oynamaktadır. Üretim faaliyetlerinin gerçekleştirilmesi ve rekabet gücünün artırılmasında giderek artan bir şekilde hizmetlere ihtiyaç duyulmaktadır. Birçok hizmet faaliyeti, diğer tüm ekonomik faaliyetleri kolaylaştırmakta ve dolayısıyla ekonomilerin genel rekabet gücü ve büyümesinde önem arz etmektedir. Ticaret ve yatırım yoluyla da uygun fiyatlı ve verimli hizmetlere erişilmesi, diğer tüm ekonomik sektörlere katkı sağlamakta ve ihracat performansını artırmaktadır (Buckley \& Majumdar, 2018). Ayrıca telekomünikasyon ve bilişim teknolojisindeki gelişmeler ile birlikte hizmetlerin görüntülenme ve satılma şekline yönelik olarak hizmet sektörü için yeni fırsatlar da ortaya çıkmıştır.

Uluslararası hizmet ticareti, ekonomilerin büyümesinde önemli bir rol oynamaktadır. Bu büyümeyi uzun vadede sürdürülebilir kılmak ve hizmet ihracatına yönelik stratejiler geliştirmek için hangi hizmetlerin karşılaştırmalı üstünlüğe sahip olduğunun belirlenmesi önemlidir (Cunha \& Forte, 2017). Bununla birlikte hizmetlerin kendine özgü özellikleri nedeniyle, ihracat rekabet gücünü ölçme hususunda kısıtlamalar söz konusudur. Bu nedenle hizmet endüstrilerinin ihracat rekabet gücünü ölçmeye yönelik çok az çalışma bulunmaktadır (Chemsripong \& Mahmood, 2008: 27-29). Literatürde özellikle mal ticaretindeki karşılaştırmalı üstünlüğün belirlenmesinde yaygın olarak kullanılan Açıklanmış Karşılaştırmalı Üstünlük (RCA) Endeksi, hizmet sektörüne uyarlanarak da kullanılmaktadır. Bu çalışma BRICS (Brezilya, Rusya, Hindistan, Çin ve Güney Afrika) ülkelerinin hizmet sektörlerinde karşılaştırmalı üstünlük durumunu RCA yaklaşımı ile incelemeyi amaçlamaktadır. BRICS ülkelerinin seçilme nedeni, özellikle son yıllarda küresel hizmet ticaretinde bu ülkelerin önemli bir yere sahip olmaları ve orta gelirli ekonomilerin en büyüğü olarak nitelendirilmeleridir (WDI, 2019). 2020 yılında BRICS ülkelerinin her birinde hizmet sektörü, yaratılan katma değer açısından en büyük sektör durumundadır. Hizmet sektörünün GSYiH içerisindeki payı Brezilya'da \%63, Çin'de \%55, Hindistan \%49, Rusya'da \%56 ve Güney Afrika'da \%61'dir. Başka bir ifadeyle BRICS ülkelerinde hizmet sektöründe yaratılan katma değer GSYiH'in yaklaşık yarısı ve/veya daha fazla düzeyindedir. BRICS ülkelerinin hepsinde sanayi ikinci, tarım ise üçüncü sektör durumundadır (WDI, 2020). Dolayısıyla analiz sonucunda elde edilen bulgular ve önerilen politikalar, BRICS ülkelerinin hizmet sektörlerinin rekabet gücünü artırmak için kullanılabilir. Makalenin planı şu şekildedir. İkinci bölümde, hizmetler sektörü ve önemi hakkında kısa bilgi verilecektir. Üçüncü bölüm, hizmetler sektöründe karşılaştırmalı üstünlük ve rekabet edebilirlik üzerine ampirik literatürü gözden geçirmektedir. Dördüncü bölümde RCA endeksine ilişkin açıklama ve ampirik sonuçlar sunulmaktadır. Son bölümde, analize ilişkin genel sonuçlar yer almaktadır.

\section{Hizmet Sektörü ve Önemi}

Klasik iktisatçılardan Adam Smith ve David Ricardo'nun hizmetleri ticareti yapılamayan ve verimli olmayan bir faaliyet olarak değerlendirmeleri ve hizmetlerin ticarete konu olmadığını varsaymaları nedeniyle bu sektör yapılan analizlerde ihmal edilmiştir. Hizmetlerin ticarî mallardan ayırt edilmesinin kolay olmayışı ve buna bağlı olarak tanımlanmalarındaki güçlük vb. sebepler dolayısıyla bu faaliyetlerin uluslararası ticaret teorisine konu olmaları da gecikmeli olmuştur. Hizmetler, geleneksel olarak uluslararası sınırların ötesinde ticareti yapılabilecek bir 
Dumrul, Y. \& Kılıçarslan, Z. (2022). BRICS Ülkelerinin Hizmet Ticaretinde Açıklanmış Karşılaştırmalı Üstünlükleri. Fiscaoeconomia, 6(1), 99-117. Doi: 10.25295/fsecon.1034136

sektör olarak görülmemiştir. Ancak bu durum, hizmetlerin üretim faaliyetlerinde ve genel ekonomide öneminin fark edilmesiyle değişmiştir. Özellikle bilgi ve iletişim teknolojisindeki gelişmeler, ülkelerin uzun mesafeler arasında hizmet ticaretini de kolaylaştırarak rekabet gücü kazanmalarına yol açmaktadır (Tapp, 2016). Böylece 1930'lara kadar önemsiz görülen hizmet sektörü, iktisadî modellerde ancak 1950'li yılların sonu ve 1960'lı yılların başı itibariyle ele alınmaya başlanmıştır. Hizmet ticaretinin öneminin ve uygulanabilirliğinin kabul edilmesi de 1 Ocak 1995'te yürürlüğe giren Hizmet Ticareti Genel Anlaşması ile olmuştur (Nath vd. 2015: 79). Günümüzde ise ekonomistler, uluslararası mal ticareti için geçerli olan temel karşılaştırmalı üstünlük teorisinin, uluslararası hizmet ticaretine de eşit derecede iyi uygulandığını varsaymaktadır (Feketekuty, 1988).

Fisher (1935) ve Colin Clark (1940) bir ekonomiyi birincil, ikincil ve üçüncül sektör olmak üzere üçlü bir sınıflamaya tabi tutmuştur. Birincil sektör, tarım, ormancılık, balıkçılık ve avcılık gibi faaliyetleri kapsamaktadır. İkincil sektör, madencilik, imalat ve gaz, elektrik ve su temini gibi faaliyetleri içermektedir. Üçüncül sektör, ticaret ve kamu hizmetlerinden oluşmaktadır (UKEssays, 2018). Ülkelerin gelişmişlik düzeyine göre ekonomik faaliyetler birincil sektörden diğer sektörlere kaymaktadır. Hizmetlerin egemen olduğu bir ekonomi, gelişmiş ülkelerin özelliği olarak görülmektedir. Her ne kadar hizmet faaliyetleri büyük ölçüde gelişmiş ülkelerle sınırlı olsa da birçok hızlı büyüyen yükselen piyasa ekonomilerinde de hizmet sektörü ön plana çıkmıştır (Nath vd. 2015: 79).

Uluslararası Hizmet Ticareti İstatistikleri El Kitabında heterojen, maddi olmayan bir ürün ve faaliyet grubunu tanımlamanın zorlukları belirtilmekte ve hizmetler "tüketici birimlerin koşullarını değiştiren veya ürün veya finansal varlıkların değişimini kolaylaştıran bir üretim faaliyetinin sonucu" olarak tanımlanmaktadır (UN, 2010). Ayrıca hizmet sektörü, mal ve hizmetin üretilmesinden tüketiciye ulaşana kadar olan faaliyetleri içermektedir (UKEssays,2018). Seyoum (2007)'ye göre, hizmetleri tanımlamak kolay değildir, çünkü hizmet faaliyetlerinin sadece soyut olmaları dışında ortak bir özellikleri bulunmamaktadır. Örneğin tarım, madencilik, imalat ve inşaat gibi sektörlerde somut nesneler üretilirken hizmetler sektörü, sadece soyut nesnelerden oluşmaktadır. Birincil ve ikincil sektörlerle ileri ve geri bağlantıları ve ayrıca ticaretle bağlantısı dolayısıyla hizmetler sektörü ekonomik büyüme için önemli bir bileşen olmaktadır. Üretim faaliyetleri ve rekabet gücü giderek artan bir şekilde hizmetlere bağımlı hale gelmektedir (UNCTAD,2010).

Hizmetler, iki yolla rekabet gücünde artışa yol açmaktadır. Birincisi, ticarete konu olan hizmetlerde karşılaştırmalı üstünlüğe sahip bir ülke bunları ihraç etmekte, böylece ekonomiyi çeşitlendirmekte ve ülkenin ihracatını artırmaktadır (Mohamed, 2020). İkincisi ise, hizmetler, tüm ekonomi için rekabet gücünün stratejik bir itici gücü olarak görülmektedir. Hizmetler, yalnızca ihracatı çeşitlendirme kaynakları olmalarından dolayı değil, aynı zamanda birçok rekabetçi ürünün üretiminde kullanılmaları sebebiyle ülkelerin rekabet gücü kazanmasında stratejik bir rol oynamaktadır. Birçok mal ihracatının rekabet gücü, yalnızca hammadde girdilerine erişiminin yanı sıra kamu hizmetleri, finansal hizmetler ve diğer ticari hizmetler dâhil olmak üzere kritik hizmet girdilerine de bağlı olmaktadır (Sáez vd., 2015). Kısaca hizmetler hem ticarete konu olmakta hem de malların üretiminde önemli bir girdi olarak yer almaktadır (WTO,2019). Bazı yazarlar hizmetlerin ekonomik yapıdaki değişimi takip edeceğine, bazıları ise hizmetlerin değer zincirleri aracılığıyla imalat ve tarımı kolaylaştırarak ve ihracat 
Dumrul, Y. \& Kılıçarslan, Z. (2022). BRICS Ülkelerinin Hizmet Ticaretinde Açıklanmış Karşılaştırmalı Üstünlükleri. Fiscaoeconomia, 6(1), 99-117. Doi: 10.25295/fsecon.1034136

geliri sağlayarak ekonomik dönüşüme öncülük edebileceğine dikkat çekmektedir (Khanna vd., 2016). Dolayısıyla hizmet sektörünün birincil ve ikincil sektörleri tamamlayan ve güçlendiren niteliğe sahip olduğu söylenebilir (UNCTAD, 2010). Örneğin, bazı hizmet sektörleri, özellikle uluslararası finans ve deniz taşımacılığı, mal ticaretinin doğal tamamlayıcısı olarak kabul edilmektedir (WTO, 2006).

\section{Literatür Taraması}

Hizmetler sektörünün ekonomik kalkınma için önemli rol oynayabileceğinin anlaşılmasıyla literatürde hizmetlere yönelik çalışmalar da hız kazanmıştır. Ülkelerin hizmet ihracatına yönelik strateji geliştirmelerinde hem rekabet gücünün ortaya konulması hem de ülkelerin hangi hizmet sektörlerinde karşılaştırmalı üstünlüğe sahip olduklarının belirlenmesi önem arz etmektedir. Ülke, sektör ve firma temelinde karşılaştırmalı üstünlüğün ölçülmesinde kullanılan yöntemlerden birisi endeks hesaplamasıdır. Çalışmamızda kullanılan yöntemle paralel olarak hizmetler sektörünün rekabet gücünü incelemek için RCA endeksini kullanan çalışmalara bu başlık altında yer verilmiştir.

Langhammer (2004), 1989-2000 dönemi için AB, ABD ve Japonya'da altı hizmet sektörü (finansal hizmetler, sigorta hizmetleri, bilgisayar ve bilgi hizmetleri, iletişim hizmetleri, kişisel, kültürel ve eğlence hizmetleri, telif hakları ve lisans ücretleri) için RCA endeksi hesaplanmıştır. Finansal hizmetler, bilgisayar ve bilgi hizmetleri, kişisel, kültürel ve eğlence hizmetleri ile telif hakları ve lisans ücretleri kategorilerinde $A B D^{\prime}$ nin karşılaştırmalı üstünlüğünün yüksek olduğu sonucuna ulaşmıştır.

Dihel vd. (2006), hizmet endüstrilerinin ihracat rekabet gücünü değerlendirmek için 19902002 dönemi için RCA endeksini hesaplamışlardır. Çalışma sonuçları, genel olarak, gelişmekte olan ülkelerin inşaat hizmetleri gibi düşük vasıflı emek yoğun hizmetlerde ve bazı durumlarda ulaşım veya seyahat hizmetleri gibi doğal kaynak yoğun hizmetlerde göreli olarak uzmanlaşmış olduğunu göstermektedir. Bununla birlikte, bazı gelişmekte olan ülkelerin, diğer ticari hizmetler gibi daha karmaşık sektörlerde karşılaştırmalı üstünlük geliştirme sürecinde olduğu da sonuçlar arasında yer almaktadır. Bu özellikle Çin, Hindistan, Malezya, Tayland, Meksika, Mısır ve Brezilya gibi ülkeler için geçerlidir.

Hisanaga (2007), ABD uluslararası hizmet ticaretinin 1989-2003 dönemi için Dünya, İngiltere, Fransa, Yunanistan, Türkiye, Almanya, Japonya, İrlanda, Rusya, Çin ile olan karşılaştırmalı üstünlük yapısını araştırmıştır. Araştırma sonuçları, ABD'nin bilgiye dayalı hizmetlerde analiz dönemi boyunca karşılaştırmalı bir üstünlüğe sahip olduğunu göstermiştir.

Seyoum (2007), 60 gelişmekte olan ülkenin 1998-2003 dönemi için seçilmiş hizmetlerde karşılaştırmalı üstünlüklerini ölçmek için RCA analizi yapmıştır. Çalışmada birçok gelişmekte olan ülkenin ulaşım ve seyahat hizmetlerinde güçlü karşılaştırmalı üstünlüğü olduğu sonucuna ulaşmıştır.

Wang vd. (2010), açıklanmış karşılaştırmalı üstünlüğü ölçmeye yönelik üç endeks kullanılarak 1998-2007 dönemi için Çin ve Hindistan'daki seyahat, ulaşım ve diğer ticari hizmetler sektörlerinin karşılaştırmalı üstünlüklerini ve rekabet gücünü analiz etmiştir. Ayrıca Çin ve Hindistan'daki bu endüstrilerin karşılaştırmalı bir incelemesini yapmıştır. Çalışmada Çin'de ulaşım ve diğer ticari hizmetler dışındaki seyahat hizmetlerinde karşılaştırmalı üstünlüğün 
Dumrul, Y. \& Kılıçarslan, Z. (2022). BRICS Ülkelerinin Hizmet Ticaretinde Açıklanmış Karşılaştırmalı Üstünlükleri. Fiscaoeconomia, 6(1), 99-117. Doi: 10.25295/fsecon.1034136

mevcut olduğu sonucuna ulaşmıştır. Hindistan'da diğer ticari hizmetler, seyahat ve ulaşım hizmetlerinden çok daha fazla karşılaştırmalı üstünlüğe sahiptir.

Barattieri (2014),1980-2009dönemi için Balassa tipi RCA endeksini hesaplamıştır. Buna göre ABD'nin hizmetlerde göreli olarak uzmanlaştığı, Almanya, Japonya ve Çin'in ise mallarda açıklanmış bir karşılaştırmalı üstünlüğe sahip olduğu sonucuna ulaşmıştır.

Nath vd. (2015), 16 hizmet kategorisi için ikili ticaret verilerini kullanarak, 1992-2010 dönemi için Çin ve Hindistan ile $A B D$ hizmet ticaretinde karşılaştırmalı üstünlüğün yapısını, gelişimini ve belirleyicilerini incelemiştir. Sonuçlar, $A B D$ 'nin seyahat ve ulaşım gibi daha geleneksel olanlar hariççoğu hizmet sektöründe karşılaştırmalı bir üstünlüğe sahip olduğunu göstermektedir.

Park (2020), 43 ülkenin (21 gelişmiş ve 22 gelişmekte olan ülke) 2007-2014 dönemi için lojistik hizmetlerin önemli olduğu endüstrilerde ulaştırma altyapısının ve lojistik kalitesinin bir karşılaştırmalı üstünlük kaynağı olup olmadığını araştırmıştır. Çalışmada bir ülkenin yüksek kaliteli ulaşım altyapısı ve lojistiği sağlama yeteneğinin, lojistik yoğun endüstrilerde karşılaştırmalı bir avantaj kaynağı olduğu sonucuna ulaşılmıştır.

Eken ve Yazıcı (2021), 2013-2019 döneminde 12 hizmet sektörü için Türkiye'nin RCA endeks değerlerini hesaplamıştır. Sonuçlar, Türkiye'nin seyahat ve taşımacılık sektörlerinde yüksek, sigorta ve bakım-onarım hizmetlerinde ise orta derecede göreli üstünlüğü olduğunu göstermektedir.

\section{Yöntem}

BRIC ülkeleri (Brezilya, Rusya, Hindistan ve Çin) kavramı ilk olarak 2001 yılının sonlarında özel bir firma (Goldman Sachs) tarafından yapılan ileriye dönük bir çalışmanın sonucu olarak ortaya çıkmıştır (Oropeza Garcia, 2014). 2010 yılında Güney Afrika'nın da BRIC ülkeler grubuna dâhil edilmesiyle, bu ülkeler BRICS ülkeleri olarak anılmaya başlanmıştır. BRICS ülkeleri, dünya nüfusunun $\% 41$ 'ini, dünya GSYiH'sinin \%24'ünü ve dünya ticaretinin yaklaşık \%16'sını oluşturan ve dünyanın önde gelen yükselen ekonomilerini bir araya getiren önemli bir gruptur (WDI, 2019). Ayrıca BRICS ülkeleri son yıllarda küresel hizmet ticaretinde de önemli bir yere sahiptir. BRICS ülkelerinin hizmet ihracatı gelişmiş ülkelerden daha hızlı büyümekte ve küresel hizmet pazarlarındaki payları da hızla genişlemektedir. Bu çalışma ile hizmet sektöründeki ticaret ve rekabet potansiyellerini belirlemek üzere BRICS ülkeler grubunun hizmet alt sektörleri bazında karşılaştırmalı üstünlükleri incelenmiştir.

Bu çalışmada BRICS ülkelerinin karşılaştırmalı üstünlüklerini ortaya koyabilmek için Balassa (1965)' in Açıklanmış Karşılaştırmalı Üstünlük (RCA) yaklaşımı hizmetler sektörüne uyarlanarak kullanılmıştır. Hizmetler sektörüne ilişkin RCA analizi, Uluslararası Hizmet Ticareti İstatistikleri El Kitabında (UN, 2010) yer alan 12 hizmet alt sektörü için yapılmıştır. Çalışmada kullanılan veriler Trademap veri tabanından temin edilerek endeks hesaplamaları yapılmıştır.

Balassa (1965) tarafından geliştirilen RCA endeksi bir ülkenin karşılaştırmalı üstünlüğünü, gözlemlenen ticaret modeliyle ortaya koymakta olup açıklanmış karşılaştırmalı üstünlüğü ele almaktadır. Sübvansiyonlar ve tarifeler gibi hükümet politikalarının ticaret kalıpları üzerindeki etkilerinin hesaba katılmaması RCA endeksinin önemli bir eksikliği olarak görülmekle birlikte 
Dumrul, Y. \& Kılıçarslan, Z. (2022). BRICS Ülkelerinin Hizmet Ticaretinde Açıklanmış Karşılaştırmalı Üstünlükleri. Fiscaoeconomia, 6(1), 99-117. Doi: 10.25295/fsecon.1034136

söz konusu endeks karşılaştırmalı üstünlük analizinde yaygın olarak kullanılmaktadır (Freckleton, 2013).

Hizmetlerin küresel ekonomide veya ulusal ekonomiler düzeyinde rolünün artmasıyla birlikte hizmetler sektöründeki karşılaştırmalı üstünlük derecesinin belirlenmesi ülkelerin görece avantajlı olduğu ve gelişmeye açık sektörlere odaklanmaları ihracattaki rekabet gücünün artmasına katkıda bulunacaktır. Orijinal RCA endeksinin hizmetler sektörüne uyarlanmış hali, belirli bir ekonominin yapısının, belirli hizmetlerin üretimindeki uzmanlaşma derecesinin ve bir ülkenin belirli bir grup/kategori üretiminde sahip olduğu açıklanmış karşılaştırmalı üstünlüğün ortaya konmasında yardımcı olacaktır (Wosiek \& Visvizi,2021).

Balassa'nın RCA endeksi şu şekilde formüle edilmektedir.

$R C A_{i t}^{j}=\frac{\left(X_{i t}^{j}\right)}{\left(X_{t}^{j}\right)} / \frac{\left(X_{i t}^{w}\right)}{\left(X_{t}^{w}\right)}$

$R C A_{i t}^{j}$ : t yılında j ülkesinin i hizmet sektörü için RCA endeksi

$\left(X_{i t}^{j}\right)$ : t yılında j ülkesinin hizmet sektörü ihracatı

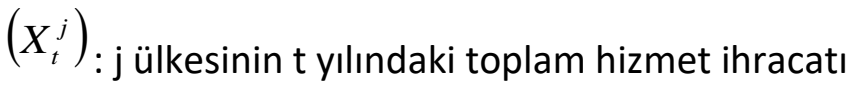

$\left(X_{i t}^{w}\right)$ : t yılında dünyanın i hizmet sektörü ihracatı

$\left(X_{t}^{w}\right)$ : t yılında dünya toplam hizmet ihracatı

Hizmet sektörüne ilişkin RCA endeksi, bir ülkenin bir "hizmet" sektörü ihracatının o ülkenin toplam hizmet ihracatındaki payının, bu "hizmetin" dünya ihracatının toplam dünya hizmet ihracatındaki payına oranını göstermektedir. Bu endeks, 0 ile $\infty$ arasında bir değer almaktadır. $R C A_{i t}^{j}>1$ ise, jülkesi t yılında i hizmet sektöründe karşılaştırmalı üstünlüğe sahiptir. Yani o hizmet sektörünün ülkenin toplam ihracatındaki payı, dünya ticaretindeki payından daha fazladır. Başka bir ifadeyle endeks değerinin 1'den büyük olması, ülkenin ilgili hizmette göreli olarak uzmanlaştığını ve dünya ortalamasına kıyasla bu tür ihracatlarda karşılaştırmalı üstünlüğe sahip olduğu anlamına gelmektedir. $R C A_{i t}^{j}<1$ ise, j ülkesi t yılında i hizmet sektöründe karşılaştırmalı bir dezavantaja sahiptir (Dihel vd. 2006; Chemsripong \& Mahmood, 2008: 29).

Karşılaştırmalı üstünlüğün derecesini göstermek üzere orijinal RCA endeksini Hinloopen ve Marrewijk (2001) daha ayrıntılı bir şekilde 4'lü bir sınıflandırmaya tabi tutmuştur. Çalışmamızda, bu sınıflandırma sistemine göre karşılaştırmalı üstünlüğün olmadığı sektörler ile zayıf, orta ve güçlü açıklanmış karşılaştırmalı üstünlüğe sahip olan sektörler belirlenmiştir. $0<\mathrm{RCA} \leq 1$ ise karşılaştırmalı üstünlük bulunmamaktadır. $1<\mathrm{RCA} \leq 2$ zayıf karşılaştırmalı üstünlüğü, $2<$ RCA $\leq 4$ orta karşılaştırmalı üstünlüğü ve $4<$ RCA güçlü karşılaştırmalı üstünlüğü ifade etmektedir (Kılıçarslan, 2019: 333). Grafik 1'de BRICS ülke grubu için 12 hizmet alt sektörüne ilişkin RCA endeks değerleri gösterilmiştir. 
Dumrul, Y. \& Kılıçarslan, Z. (2022). BRICS Ülkelerinin Hizmet Ticaretinde Açıklanmış Karşılaştırmalı Üstünlükleri. Fiscaoeconomia, 6(1), 99-117. Doi: 10.25295/fsecon.1034136

\section{Grafik 1: BRICS Ülke Grubu İçin Hizmet Sektörlerine ilişkin RCA Endeks Değerleri}

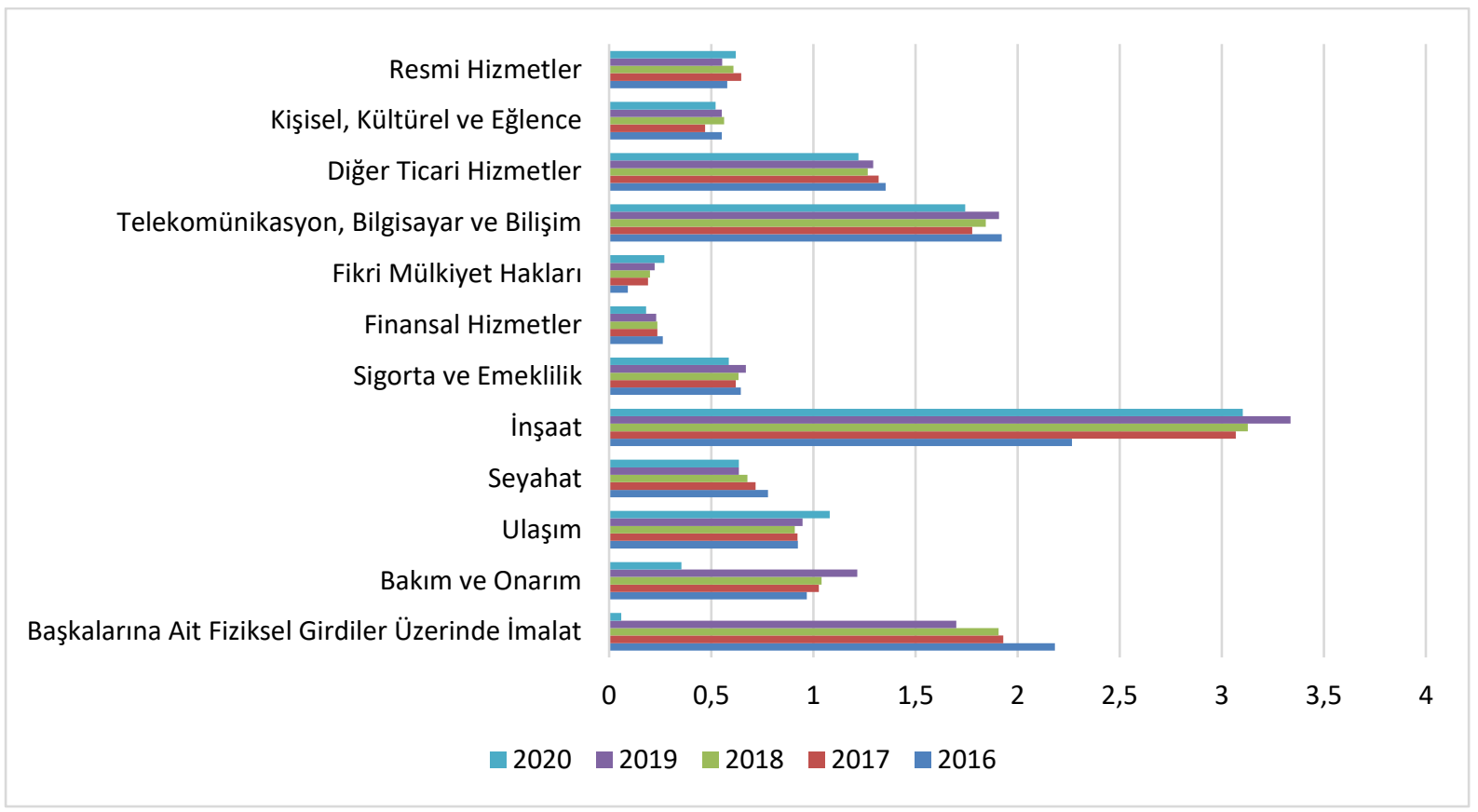

Grafik 1'de yer alan sonuçlara göre başkalarına ait fiziksel girdiler üzerinde imalat hizmetlerinde (2020 yılı hariç), bakım ve onarım hizmetlerinde (2016 ve 2020 yılları hariç), ulaşım hizmetlerinde (sadece 2020 yılı), inşaat hizmetlerinde, telekomünikasyon, bilgisayar ve bilişim hizmetlerinde ve diğer ticari hizmetlerde, BRICS ülkelerinin dünya karşısında rekabet üstünlügü bulunmaktadır. Bununla birlikte Hinloopen ve Marrewijk (2001)'in sınıflandırmasına göre BRICS ülke grubunun karşılaştırmalı üstünlüğe sahip olduğu sektörler içerisinde inşaat hizmetlerinde orta derecede karşılaştırmalı üstünlük söz konusu iken, diğer sektörlerde zayıf bir karşılaştırmalı üstünlük bulunmaktadır. BRICS ülkeleri tüm yıllarda seyahat hizmetleri, sigorta ve emeklilik hizmetleri, finansal hizmetler, fikri mülkiyet hakları, kişisel, kültürel ve eğlence hizmetleri ve resmi hizmetlerde ise karşılaştırmalı dezavantaja sahiptir.

Son kırk yıllık dönemde, Çin'in ekonomik büyümesi, ucuz işgücüne dayalı ihracat tarafından yönlendirilmiştir. Günümüzde işgücü maliyetlerinin artması ve işgücünün giderek daha eğitimli hale gelmesi sebepleriyle Çin, üretim ağırlıklı bir ekonomik modelden hizmet odaklı bir ekonomik modele geçiş yapmıştır. 2020 yılında hizmetler Çin'in GSYiH'sinin \%55'ini oluşturmakta, toplam ekonomik büyümesinin \%60'ına katkıda bulunmakta ve uluslararası piyasalardaki rekabet gücünü artırmaktadır (Liu, 2021). Çin'in 12 hizmet alt sektörüne ilişkin RCA analizi sonuçları Grafik 2'de verilmiştir. 
Dumrul, Y. \& Kılıçarslan, Z. (2022). BRICS Ülkelerinin Hizmet Ticaretinde Açıklanmış Karşılaştırmalı Üstünlükleri. Fiscaoeconomia, 6(1), 99-117. Doi: 10.25295/fsecon.1034136

Grafik 2: Çin İçin Hizmet Sektörlerine ilişkin RCA Endeks Değerleri

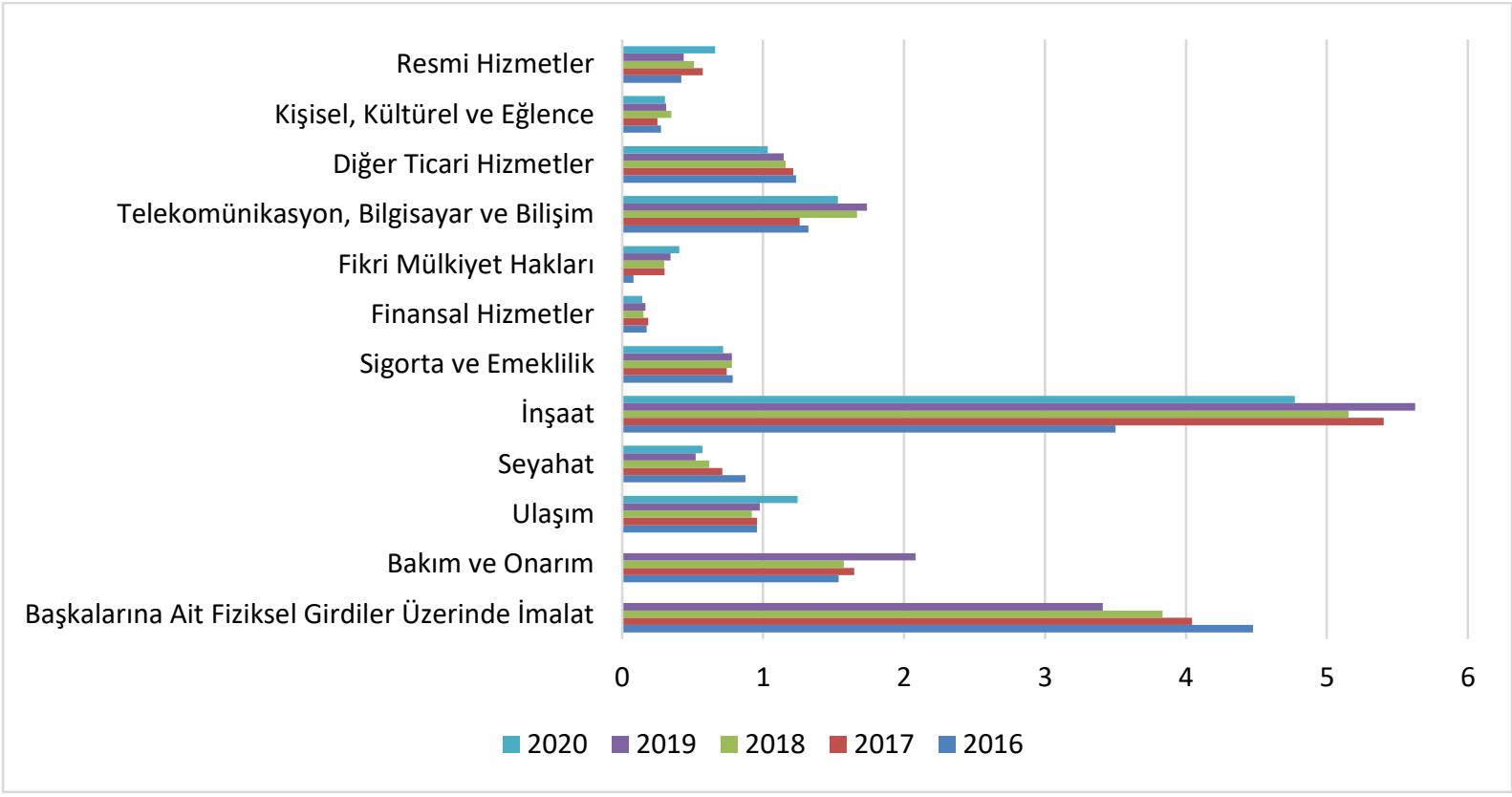

Grafik 2'den de görüleceği üzere Çin, seyahat hizmetleri, sigorta ve emeklilik hizmetleri, finansal hizmetler, fikri mülkiyet hakları, kişisel, kültürel ve eğlence hizmetleri, resmi hizmetler sektörlerinde karşılaştırmalı dezavantaja sahiptir. Başkalarına ait fiziksel girdiler üzerinde imalat hizmetleri, bakım ve onarım hizmetleri, inşaat hizmetleri, telekomünikasyon, bilgisayar ve bilişim hizmetleri ve diğer ticari hizmetlerde ise analiz döneminin tamamında ve ulaşım hizmetlerinde ise sadece 2020 yılında karşılaştırmalı üstünlüğe sahiptir. Hinloopen ve Marrewijk (2001)'in sınıflandırmasına göre değerlendirdiğimizde Çin'in karşılaştırmalı üstünlüğe sahip olduğu hizmetler içerisinde başkalarına ait fiziksel girdiler üzerinde imalat hizmetlerinde 2016 ve 2017 yıllarında güçlü karşılaştırmalı üstünlüğe sahip olduğu ancak diğer yıllarda güçlü karşılaştırmalı üstünlüğün yerini orta dereceli karşılaştırmalı üstünlüğün aldığı görülmektedir. İnşaat hizmetlerinde ise 2016 yılında orta derecede karşılaştırmalı üstünlük söz konusu iken Çin'in diğer yıllarda güçlü karşılaştırmalı üstünlüğe sahip olduğu dikkat çekmektedir. Karşılaştırmalı üstünlüğe sahip olunan diğer sektörlerde ise zayıf karşılaştırmalı üstünlük söz konusudur. Bu sonuçlar hizmet odaklı bir ekonomik modele geçiş yapan Çin'de zayıf karşılaştırmalı üstünlüğün olduğu sektörlerde iyileştirmeye gidilmesi gerektiğini göstermektedir.

Hindistan'da hizmet sektörü, GSYiH'sinin yaklaşık olarak \%49'unu oluşturmakla birlikte, dünyanın en hızlı büyüyen hizmet sektörüdür. Bilgi tabanlı hizmetlerin oluşturduğu kendine özgü yetkinlikleri ve rekabet avantajı sayesinde Hindistan dünyada gelişen benzersiz bir pazar haline dönüşmüştür (WDI, 2020; Deloitte, 2017: 5). Hizmet sektörü, Hindistan'ın GSYiH'sinde yalnızca baskın sektör olmakla kalmayıp, aynı zamanda önemli yabancı yatırımları da çekmiş, ihracata önemli ölçüde katkıda bulunmuş ve büyük ölçekli istihdam sağlamıştır. Ayrıca hizmet ihracatı, Hindistan'ın toplam ihracatında önemli bir yere sahiptir (IBEF, 2021). Hindistan için 12 hizmet alt sektörüne ilişkin RCA analizi sonuçları Grafik 3'te verilmiştir. 
Dumrul, Y. \& Kılıçarslan, Z. (2022). BRICS Ülkelerinin Hizmet Ticaretinde Açıklanmış Karşılaştırmalı Üstünlükleri. Fiscaoeconomia, 6(1), 99-117. Doi: 10.25295/fsecon.1034136

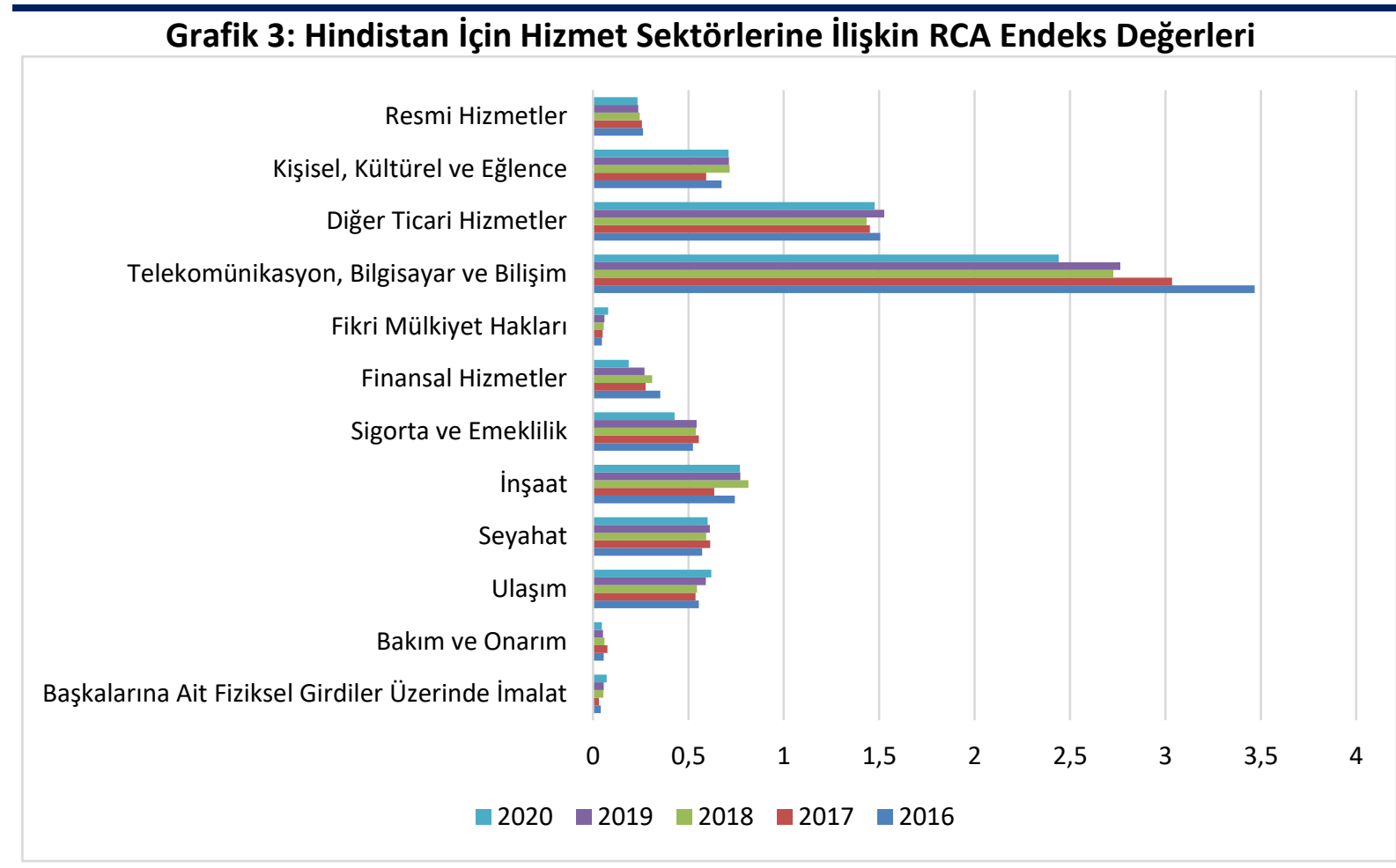

Grafik 3'ten görüleceği gibi Hinloopen ve Marrewijk (2001)'in sınıflandırması dikkate alındığında Hindistan telekomünikasyon, bilgisayar ve bilişim hizmetlerde orta derecede karşılaştırmalı üstünlüğe, diğer ticari hizmetlerde ise zayıf karşılaştırmalı üstünlüğe sahip bulunmaktadır. Bu sektörler dışındaki 10 hizmet alt sektöründe karşılaştırmalı olarak dezavantajlı durumdadır. Başka bir ifadeyle Hindistan diğer grup ülkeleri ile kıyaslandığında ele alınan hizmet alt sektörlerinde büyük ölçüde dezavantajlı gözükmektedir. Hindistan'ın toplam ihracatında önemli bir yere sahip olan hizmet sektörü, hizmet alt sektörleri itibariyle incelendiğinde telekomünikasyon, bilgisayar ve bilişim hizmetleri ile diğer ticari hizmetler dışındaki alt sektörlerde rekabet avantajı elde edemediği görülmektedir.

Rusya'da Sovyet dönemindeki merkezi planlama uygulaması nedeniyle imalat ve ağır sanayi sektörlerine ağırık verilmiş, hizmet sektörleri verimli olmayan yapıları nedeniyle göz ardı edilmiştir (UiB, 2019). Rusya'da Sovyetler Birliği'nin çöküşü sonrasında hizmet sektörleri önemli bir büyüme göstermiş olup, GSYiH'sinin yaklaşık olarak \%56'sını oluşturmaktadır (WDI, 2020). Rusya'nın 12 hizmet alt sektörüne ilişkin RCA analizi sonuçları Grafik 4'te verilmiştir. 
Dumrul, Y. \& Kılıçarslan, Z. (2022). BRICS Ülkelerinin Hizmet Ticaretinde Açıklanmış Karşılaştırmalı Üstünlükleri. Fiscaoeconomia, 6(1), 99-117. Doi: 10.25295/fsecon.1034136

Grafik 4: Rusya İçin Hizmet Sektörlerine İlişkin RCA Endeks Değerleri

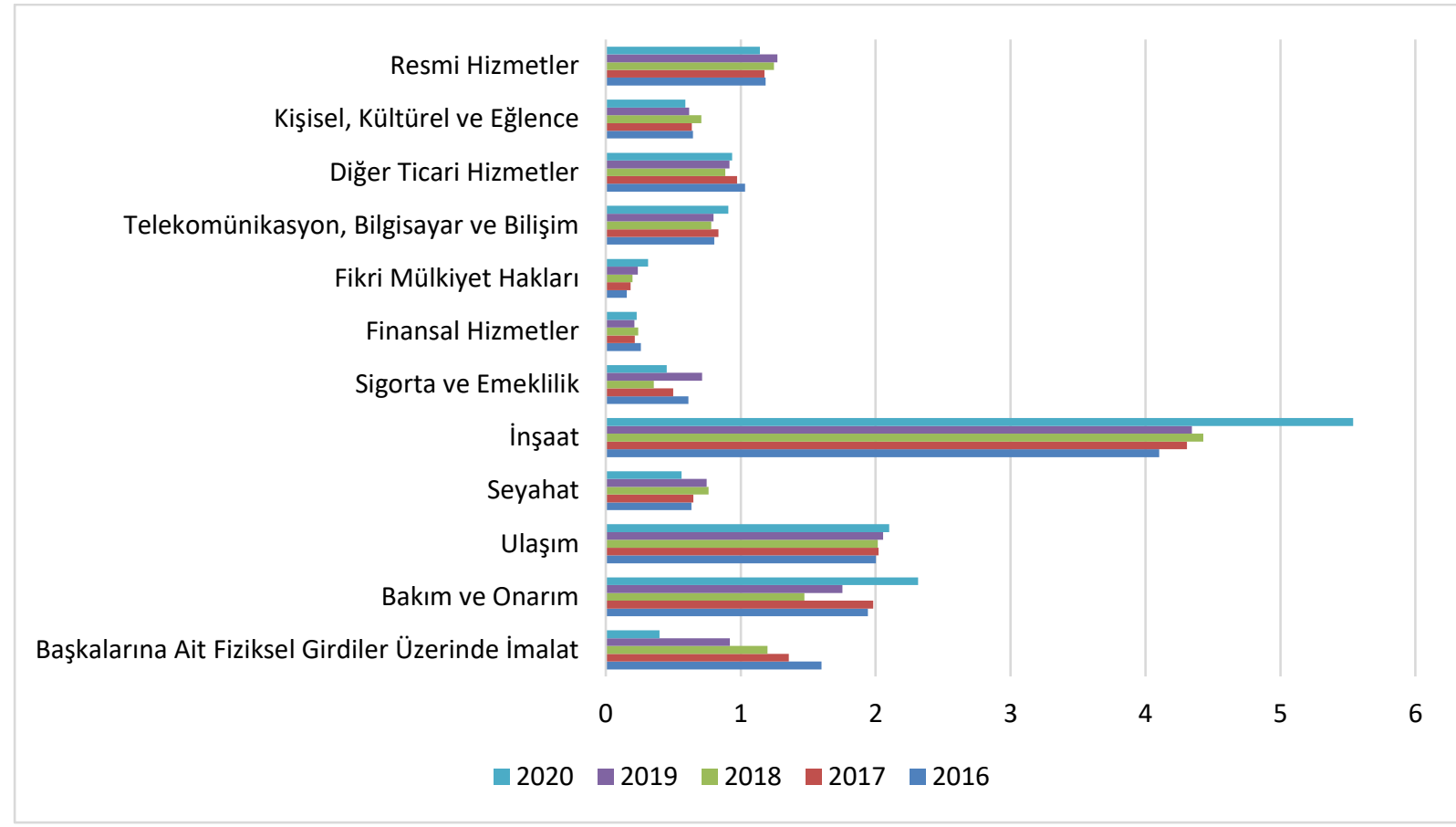

Grafik 4'te yer alan sonuçlara göre, Rusya için seyahat hizmetleri, sigorta ve emeklilik hizmetleri, finansal hizmetler, fikri mülkiyet hakları, telekomünikasyon, bilgisayar ve bilişim hizmetleri, diğer ticari hizmetler (2016 yılı hariç) ile kişisel, kültürel ve eğlence hizmetleri karşılaştırmalı dezavantajlı olduğu sektörlerdir. Başkalarına ait fiziksel girdiler üzerinde imalat (2019 ve 2020 yılları hariç), bakım ve onarım hizmetleri, ulaşım hizmetleri, inşaat hizmetleri, diğer ticari hizmetler (sadece 2016 yılı) ve resmi hizmetlerde karşılaştırmalı üstünlüğe sahiptir. Inşaat hizmetlerindeki karşılaştırmalı üstünlüğün derecesinin güçlü olması dikkat çekicidir. Bununla birlikte karşılaştırmalı üstünlüğe sahip olunan sektörler arasında ulaşım hizmetlerinde orta derece, diğer sektörlerde ise zayıf karşılaştırmalı üstünlük söz konusudur.

Hizmet sektörü Brezilya GSYiH'sinin yaklaşık olarak \%63'ünü oluşturmaktadır (WDI, 2020). Ayrıca Brezilya'da hizmetler sektörünün genel itibariyle iç pazara yönelik olması ve düşük verimliliğe sahip olması ihracat pazarlarında rekabet gücünü azaltmaktadır (OECD, 2016). Brezilya için 12 hizmet alt sektörüne ilişkin RCA analizi sonuçları Grafik 5'te verilmiştir. 
Dumrul, Y. \& Kılıçarslan, Z. (2022). BRICS Ülkelerinin Hizmet Ticaretinde Açıklanmış Karşılaştırmalı Üstünlükleri. Fiscaoeconomia, 6(1), 99-117. Doi: 10.25295/fsecon.1034136

Grafik 5. Brezilya İçin Hizmet Sektörlerine İlişkin RCA Endeks Değerleri

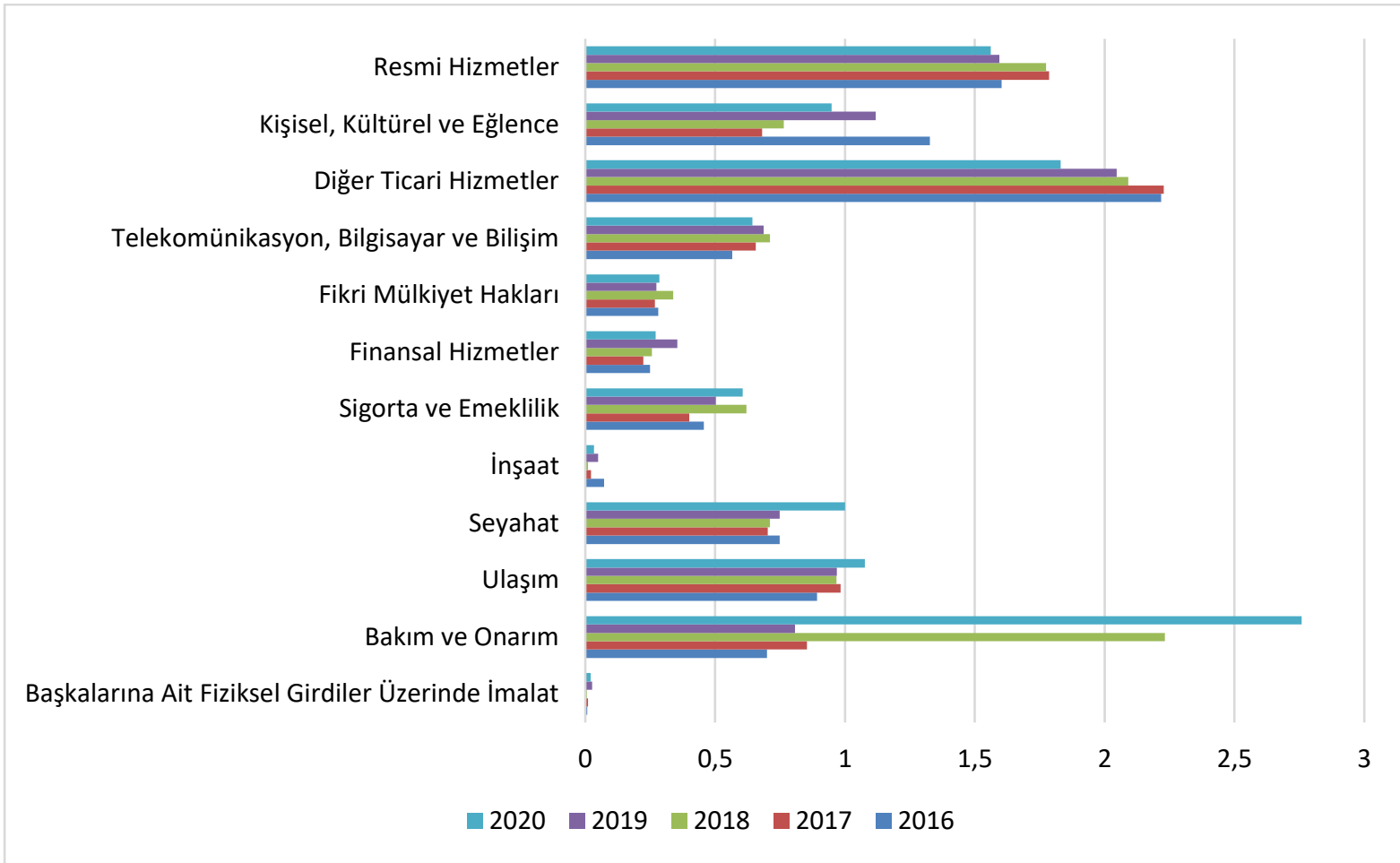

Grafik 5'te yer alan sonuçlara göre Brezilya'nın tüm yıllarda karşılaştırmalı dezavantaja sahip olduğu sektörler başkalarına ait fiziksel girdiler üzerinde imalat hizmetleri, bakım ve onarım hizmetleri (2018 ve 2020 yılları hariç), seyahat hizmetleri, inşaat hizmetleri, sigorta ve emeklilik hizmetleri, finansal hizmetler, fikri mülkiyet hakları, telekomünikasyon, bilgisayar ve bilişim hizmetleridir. Bununla birlikte Brezilya, diğer ticari hizmetlerde (2020 yılı hariç) orta, kişisel, kültürel ve eğlence hizmetleri (2017 ve 2018 yılları hariç) ve resmi hizmetlerde zayıf karşılaştırmalı üstünlüğe sahiptir.

Güney Afrika'da hizmetler sektörünün GSYiH'deki payı yaklaşık olarak \%61'dir (WDI, 2020). Bununla birlikte Güney Afrika'da hizmet sektörü, düşük teknolojili faaliyetleri kapsamakta ve iç pazarla sınırlı bulunmaktadır. Bu durum çoğunlukla hizmet ticaretinin yapılamayacağı veya ihraç edilemeyeceği anlamına gelmektedir (Kruss \& Sithole, 2018). Güney Afrika için 12 hizmet alt sektörüne ilişkin RCA analizi sonuçları Grafik 6'da verilmiştir. 
Dumrul, Y. \& Kılıçarslan, Z. (2022). BRICS Ülkelerinin Hizmet Ticaretinde Açıklanmış Karşılaştırmalı Üstünlükleri. Fiscaoeconomia, 6(1), 99-117. Doi: 10.25295/fsecon.1034136

Grafik 6: Güney Afrika İçin Hizmet Sektörlerine İlişkin RCA Endeks Değerleri

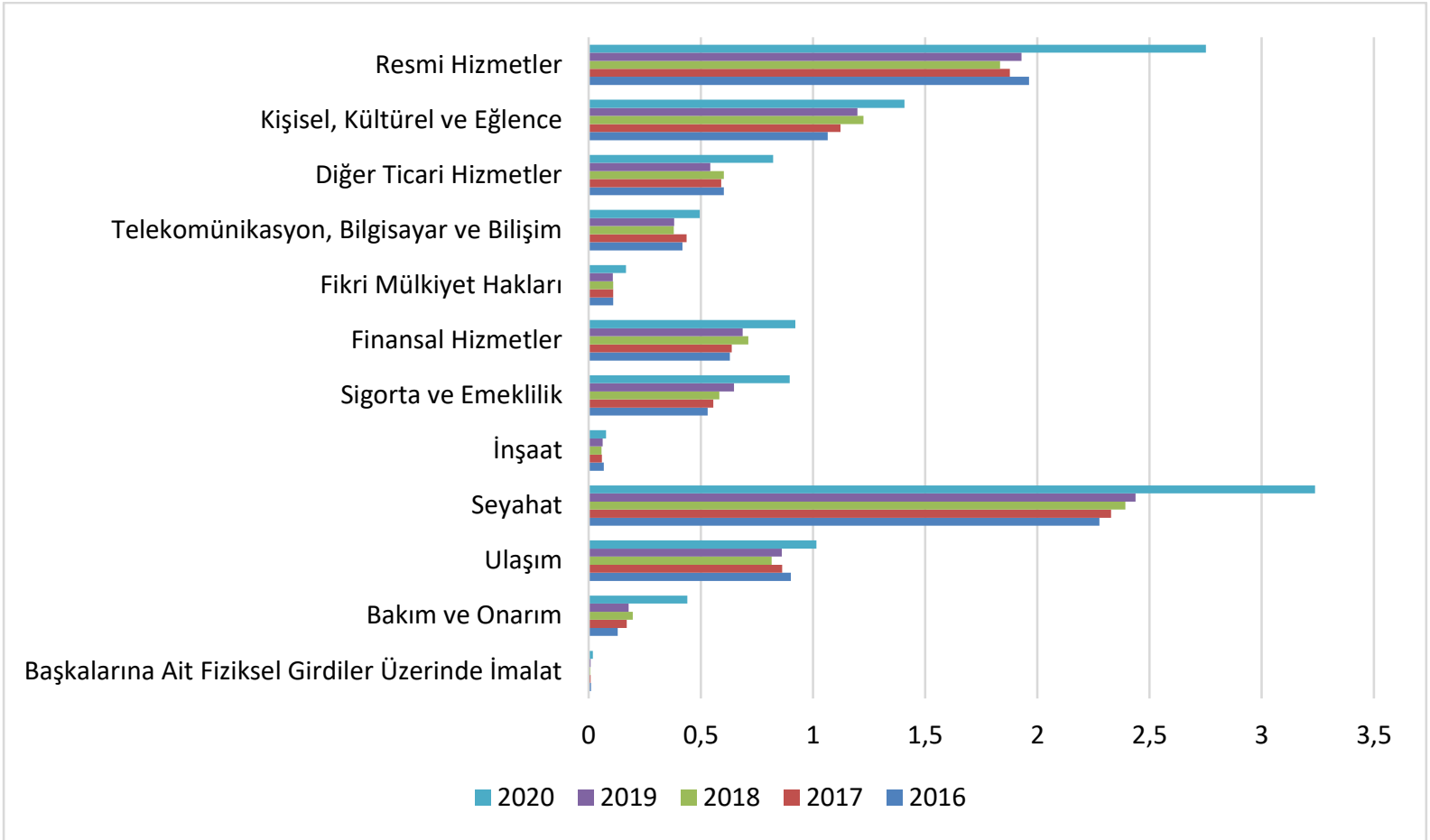

Grafik 6'dan görüleceği gibi Güney Afrika, seyahat hizmetlerinde orta, kişisel, kültürel ve eğlence hizmetleri ve resmi hizmetlerde dünya karşısında zayıf karşılaştırmalı üstünlüğe sahip bulunmaktadır. Başkalarına ait fiziksel girdiler üzerinde imalat hizmetleri, bakım ve onarım hizmetleri, ulaşım hizmetleri (2020 yılı hariç), sigorta ve emeklilik hizmetleri, finansal hizmetler, fikri mülkiyet haklarına ilişkin hizmetler, telekomünikasyon, bilgisayar ve bilişim hizmetleri ve diğer ticari hizmetlerde tüm yıllarda karşılaştırmalı dezavantajlı durumdadır.

\section{Sonuç}

Üç sektörlü makroekonomik teoriye göre, üç ana ekonomik sektörden biri hizmet sektörüdür. Her ne kadar hizmet sektörü üçüncül sektör olarak kabul edilse de, küresel ekonominin en hızlı gelişen sektörlerinden birisidir. Dolayısıyla hiçbir şekilde hizmet sektörü ekonomik önem açısından üçüncü sırada yer almamaktadır. Hizmetlerin üretim, dağıtım ve tüketim süreçlerinin küresel olarak daha kolay olması ülkeleri uluslararası hizmet ticaretine ağırlık vermesine yol açmakta bu da ülkelerin rekabet gücü kazanımlarında hizmet sektörünü ön plana çıkarmaktadır. Son yıllarda hem gelişmiş hem de gelişmekte olan ülkelerin hizmet ticaretinde önemli artışlar meydana gelmiştir. Örneğin BRICS ülkelerinin yaratılan katma değer açısından GSYIH'sinin yarısından fazlasını hizmet sektörü oluşturmaktadır.

Çalışma sonucunda 2016-2020 döneminde BRICS ülke grubunun 12 hizmet alt sektöründeki RCA endeks hesaplamasından elde edilen bulgular şu şekilde özetlenebilir. BRICS ülkelerinin dünya karşısında karşılaştırmalı üstünlüğe sahip olduğu sektörler şunlardır: inşaat hizmetleri, telekomünikasyon, bilgisayar ve bilişim hizmetleri ve diğer ticari hizmetler. Bu sektörler içerisinde özellikle inşaat hizmetleri diğer iki sektöre göre daha avantajlı durumdadır. BRICS ülkeleri tekil olarak değerlendirildiğinde Çin başkalarına ait fiziksel girdiler üzerine imalat ve inşaat hizmetlerinde, Rusya ise inşaat hizmetlerinde güçlü karşılaştırmalı üstünlüğe sahip iken 
Dumrul, Y. \& Kılıçarslan, Z. (2022). BRICS Ülkelerinin Hizmet Ticaretinde Açıklanmış Karşılaştırmalı Üstünlükleri. Fiscaoeconomia, 6(1), 99-117. Doi: 10.25295/fsecon.1034136

ele alınan dönemde Hindistan, Brezilya ve Güney Afrika'nın 12 hizmet alt sektörü içerisinde güçlü karşılaştırmalı üstünlüğe sahip olduğu sektör bulunmamaktadır.

BRICS ülkelerinde güçlü karşılaştırmalı üstünlüğe sahip olan hizmetlerde sürdürülebilirliği sağlamak ve zayıf ve orta derecede karşılaştırmalı üstünlüğe sahip olunan hizmetlerde karşılaştırmalı üstünlüğün derecesini yükseltmek için ilgili sektörlere ilişkin yatırımların teşviklerle desteklenmesi ve hizmet sektörünün üretkenliğini ve verimliliğini artırmaya yönelik beşeri sermaye yatırımlarına öncelik verilmesi uygun olacaktır. Bu çalışmada BRICS ülkelerinin hizmet sektöründeki karşılaştırmalı üstünlük durumu incelenmiş ve alt sektörler itibariyle açıklanmış verilerle karşılaştırmalı üstünlük yapısı ortaya konulmuş olup karşılaştırmalı üstünlüğün nedenlerine değinilmemiştir. Gelecek çalışmalarda hizmet sektöründeki karşılaştırmalı üstünlüğün nedenleri farklı metodolojiler kullanılarak analiz edilebilir.

\section{Kaynakça}

Balassa, B. (1965). Trade liberalisation and "revealed" comparative advantage. The Manchester School, 33(2), 99-123.

Barattieri, A. (2014). Comparative advantage, service trade, and global imbalances. Journal of International Economics, 92(1), 1-13.

Buckley, P.,\& Majumdar, R. (2018). The services power house: Increasingly vital to world economic growth. Deloitte Insights, 12, 1-20.

Chemsripong, S.,\& Mahmood, A. (2008). Services exports: An evolution an devaluation of Thailands services exports in the context of ASEAN-5. International Business \& Economics Research Journal (IBER), 7(9), 27-34.

Cunha, N.,\& Forte, R. (2017). The Comparative advantages in the services sector of developing economies. Global Economy Journal, 17(4), https://doi.org/10.1515/gej-2017-0063.

Deloitte (2017). India Services Sector-A multi-trillion dollar opportunity for global symbiotic growth. Global Exhibition on Services-The India Opportunity, 17-20 April, https://www2.deloitte.com/in/en/pages/industries/articles/india-servicessector.html

Dihel, N., Eschenbach, F., \& Shepherd, B. (2006)., South-South Services Trade, OECD Trade Policy Papers, No. 39, OECD Publishing, Paris, https://doi.org/10.1787/314720701370.

Eken, A. A.,\& Yazıcı, D. (2021). Structure of Turkey's export of services. https://tcmbblog.org/wps/wcm/connect/blog/en/main+menu/analyses/structure+of +turkeys+exports+of+services.

Liu, I. (2021), China's Service sector at a glance, April 12, https://www.eurobiz.com.cn/chinasservice-sector-at-a-glance/

Feketekuty, G. (1988). International Trade in Services: An Overview and Blueprint for Negotiations, Cambridge, Mass.: American Enterprise Institute /Ballinger.

Freckleton, M. (2013). Revealed comparative advantage of services exports in Cariforum countries. Ibero-americana, 43(1/2), 169-183. 
Dumrul, Y. \& Kılıçarslan, Z. (2022). BRICS Ülkelerinin Hizmet Ticaretinde Açıklanmış Karşılaştırmalı Üstünlükleri. Fiscaoeconomia, 6(1), 99-117. Doi: 10.25295/fsecon.1034136

Hinloopen, J.,\& Marrewijk C. V. (2001). On the empirical distribution of the balassa index. Review of World Economics / Weltwirtschaftliches Archiv, 137, 1-35.

Hisanaga, M. (2007). Comparative advantage structure of US international services. KIER Discussion

Paper, 633, https://repository.kulib.kyotou.ac.jp/dspace/bitstream/2433/129547/1/DP633.pdf.

IBEF (2021), Indian Services Industry Report, NOVEMBER, https://www.ibef.org/industry/services.aspx

Khanna, A., Papadavid, P., Tyson, J., \& te Velde, D. W. (2016). The role of services in economic transformation-with an application to Kenya. Supporting Economic Transformation. https://set.odi.org/wp-content/uploads/2016/02/The-Role-of-Services-in-EconomicTransformation_Kenya.pdf.

Kılıçarslan, Z. (2019). Doğrudan Yabancı Yatırım Girişlerinde Açıklanmış Karşılaştırmalı Üstünlük Analizi. IBAD Sosyal Bilimler Dergisi, Ekim 2019 Özel Sayısı, 326-339.

Kruss, G., \& Sithole, M. (2018). How South Africa's services sector can help tackle poverty and inequality. https://theconversation.com/how-south-africas-services-sector-can-helptackle-poverty-and-inequality-96741

Langhammer, R. J. (2004). Revealed comparative advantages in the services trade of the United States, the European Union and Japan: what do they tell us?. The journal of World investment \& trade, 5(6), 887-896.

Mohamed, A. (2020). Why trade in services matters for development and inclusiveness in Africa. $\quad$ http://www.ipsnews.net/2020/02/trade-services-matters-developmentinclusiveness-africa/

Nath, H. K., Liu, L., \& Tochkov, K. (2015). Comparative advantages in US bilateral services trade with China and India. Journal of Asian Economics, 38, 79-92.

OECD (2016). Services and Performance of The Brazilian Economy: Analysis and Policy Options, https://economiadeservicos.com/wp-content/uploads/2015/04/STRI-Brazil-policypaper.pdf

Oropeza Garcia, A. (2014). The role of China and the BRICS project. Mexican law review, 7(1): 109-136.

Park, S. (2020). Quality of transport infrastructure and logistics as source of comparative advantage. Transport Policy, 99, 54-62.

Sáez, S., Taglioni, D., Van der Marel, E., Hollweg, C. H., \& Zavacka, V. (2015). Valuing services in trade: A toolkit for competitiveness diagnostics. World Bank Publications.

Seyoum, B. (2007). Revealed comparative advantage and competitiveness in services: A study with special emphasis on developing countries. Journal of Economic Studies. 34(5), 376-388.

Tapp, S. (2016). The growing importance of services in Canadian trade, Policy Options Politiques. https://policyoptions.irpp.org/fr/magazines/aout-2016/the-growingimportance-of-services-in-canadian-trade/ 
Dumrul, Y. \& Kılıçarslan, Z. (2022). BRICS Ülkelerinin Hizmet Ticaretinde Açıklanmış Karşılaştırmalı Üstünlükleri. Fiscaoeconomia, 6(1), 99-117. Doi: 10.25295/fsecon.1034136

UiB (2019). Rusya Federasyonu Ülke Raporu (Meyve Sebze Mamulleri Sektörü Açısından), Uludağ ihracatçı Birlikleri Genel Sekreterliği Arge Şubesi https://uib.org.tr/tr/kbfile/rusya-federasyonu-ulke-raporu-msm-sektoru-acsndan

UKEssays. (November 2018). Role of service sector in economic development. Retrieved from https://www.ukessays.com/essays/economics/role-service-sector-economic8066.php?vref=1.

UNCTAD, (2010). Services, trade and development, https://unctad.org/topic/tradeagreements/services.

United Nations (UN), (2010) Manual on statistics of international trade in services 2010. New York: United Nations Publication.

Wang, Y., Cui, L., Ding, L., \& Ma, S. (2010, June). The empirical study of comparative advantage of Chinese and Indian service industries: A comparative perspective. In 2010 IEEE International Conference on Management of Innovation \& Technology (pp. 384-389).

WDI (2020), World development indicators, Erişim Adresi: https://data.worldbank.org/indicator/NV.SRV.TOTL.ZS?end=2020\&start=2016, Erişim Tarihi: 07.8.2021.

WDI, World Development Indicators, (2019), In 2017, services were the main driver of economic growth in BRICS, https://datatopics.worldbank.org/world-developmentindicators/stories/services-drive-economic-growth.html

Wosiek R, \& Visvizi A. (2021). The VWRCA Index: Measuring a country's comparative advantage and specialization in services. The case of Poland. Economies, 9(2): 48. https://doi.org/10.3390/economies9020048

WTO (2006). The general agreement on trade in services, https://newdoc.nccu.edu.tw/teasyllabus/1082351729001/W1\%20Introducion_to_GA TS.WTO.pdf.

WTO, (2019). World Trade Statistical Review,Erişim Adresi: https://www.wto.org/english/res_e/statis_e/wts2019_e/wts2019_e.pdf, Erişim Tarihi: 09.10.2021.

Etik Beyanı: Bu çalışmanın tüm hazırlanma süreçlerinde etik kurallara uyulduğunu yazarlar beyan eder. Aksi bir durumun tespiti halinde Fiscaoeconomia Dergisinin hiçbir sorumluluğu olmayıp, tüm sorumluluk çalışmanın yazarlarına aittir.

Yazar Katkıları (Eğer makalenin birden fazla yazarı varsa doldurulacaktır): Yazar katkısı açıklaması için örnek: Zerrin KILIÇARSLAN, çalışmada Giriş, Sonuç, Kuramsal Çerçeve ve Ampirik Literatür bölümlerinde ve veri toplama aşamalarında katkı sağlamıştır. Yasemin DUMRUL, çalışmada Giriş, Veri Seti, Ekonometrik Metodoloji ve Bulgular bölümlerinde ve veri toplama ile analiz aşamalarında katkı sağlamıştır. 1. yazarın katkı oranı: \%50, 2. yazarın katkı oranı: \%50.

Çıkar Beyanı: Yazarlar arasında çıkar çatışması yoktur. (Birden fazla yazar varsa doldurulacaktır) 
Ethics Statement: The authors declare that ethical rules are followed in all preparation processes of this study. In case of detection of a contrary situation, Fiscaoeconomia has no responsibility and all responsibility belongs to the authors of the study.

Author Contributions: Zerrin KILIÇARSLAN contributed to the study in Introduction, Conclusion, Theoretical Framework and Empirical Literature sections and data collection stages. Yasemin DUMRUL contributed to the study in the Introduction, Data Set, Econometric Methodology and Results sections, in the data collection and analysis stages. 1st author's contribution rate: $50 \%$, 2 nd author's contribution rate: $50 \%$.

Conflict of Interest: There is no conflict of interest between the authors. 
Dumrul, Y. \& Kılıçarslan, Z. (2022). BRICS Ülkelerinin Hizmet Ticaretinde Açıklanmış Karşılaştırmalı Üstünlükleri. Fiscaoeconomia, 6(1), 99-117. Doi: 10.25295/fsecon.1034136

\section{Revealed Comparative Advantages in the Services Trade of BRICS Countries}

\section{Yasemin DUMRUL \& Zerrin KILIÇARSLAN}

\section{Extended Abstract}

The services sector, which is a key factor in economic transformation and structural change in both developed and developing countries, plays an increasingly important role in the growth and development of countries by providing opportunities for income growth, productivity, employment, investment and trade. There is an increasing need for services in the realization of production activities and increasing competitiveness.Many service activities facilitate all other economic activities and are therefore important to the overall competitiveness and growth of economies.Access to affordable and efficient services through trade and investment also contributes to all other economic sectors and increases export performance(Buckley \& Majumdar, 2018). In addition, with the developments in telecommunications and information technology, new opportunities have emerged for the service sector regarding the way services are displayed and sold.

International trade in services plays an important role in the growth of economies. It is important to determine which services have a comparative advantage in making this growth sustainable in the long term and in developing strategies for service exports(Cunha \& Forte, 2017). However, due to the unique characteristics of services, there are restrictions on measuring export competitiveness. Therefore, there are very few studies to measure the export competitiveness of service industries (Chemsripong \& Mahmood, 2008: 27-29).This study aims to examine the comparative advantage in service sectors of BRICS (Brazil, Russia, India, China and South Africa) countries with the Revealed Comparative Advantage (RCA) approach. The reason for choosing the BRICS countries is that these countries have an important place in the global service trade, especially in recent years, and they are characterized as the largest middle-income economies(WDI, 2019). In each of the BRICS countries in 2020, the service sector is the largest sector in terms of added value created.The share of the service sector in GDP is $63 \%$ in Brazil, 55\% in China, $49 \%$ in India, 56\% in Russia, and $61 \%$ in South Africa. In other words, the added value created in the service sector in the BRICS countries is about half of the GDP and/or more.In all BRICS countries, the industry is the second sector and agriculture is the third sector(WDI, 2020). Therefore, the findings obtained as a result of the analysis and the proposed policies can be used to increase the competitiveness of the service sectors of the BRICS countries.

With the understanding that the services sector can play an important role in economic development, studies on services have also gained momentum in the literatureln developing strategies for service exports, it is important both to reveal the competitiveness and to determine in which service sectors the countries have a comparative advantage. One of the methods used to measure comparative advantage on the basis of country, sector, and firm is index calculation.In this study, Balassa's (1965) Revealed Comparative Advantage (RCA) approach was used by adapting it to the services sector in order to reveal the comparative advantages of the BRICS countries.RCA analysis of the services sector was made for 12 service sub-sectors included in the International Services Trade Statistics Manual (UN, 2010). The RCA index for the service sector shows the ratio of a country's share of exports of a "service" sector 
Dumrul, Y. \& Kılıçarslan, Z. (2022). BRICS Ülkelerinin Hizmet Ticaretinde Açıklanmış Karşılaştırmalı Üstünlükleri. Fiscaoeconomia, 6(1), 99-117. Doi: 10.25295/fsecon.1034136

in that country's total service exports to the share of world exports of that "service" in total world exports of services. This index takes a value between 0 and $\infty$.If $R C A_{i t}^{j}>1$, country j has a comparative advantage in service sector $i$ in year $t$. In other words, the share of that service sector in the country's total exports is higher than its share in world trade. In other words, if the index value is greater than 1 , it means that the country specializes in the relevant service relatively and has a comparative advantage in such exports compared to the world average. If $R C A_{i t}^{j}<1$, country $\mathrm{j}$ has a comparative disadvantage in service sector $\mathrm{i}$ in year t.In order to show the degree of comparative advantage, Hinloopen and Marrewijk (2001) subjected the original RCA index to a 4-fold classification in more detail.In our study, according to this classification system, sectors that do not have comparative advantage and sectors that have weak, moderate, and strong comparative advantage were determined.If $0<R C A \leq 1$, there is no comparative advantage. $1<\mathrm{RCA} \leq 2$ denotes weak comparative advantage, $2<\mathrm{RCA}$ $\leq 4$ moderate comparative advantage, and $4<$ RCA strong comparative advantage.

As a result of the study, the findings obtained from the calculation of the RCA index in 12 service sub-sectors for the BRICS country group and each BRICS country in the period of 20162020 can be summarized as follows. The sectors in which the BRICS countries have a comparative advantage over the world are: construction services, telecommunications, computer and information services and other business services. Among these sectors, especially construction services are more advantageous than the other two sectors.

When the BRICS countries are evaluated individually, China has a comparative disadvantage in travel services, insurance and pension services, financial services, charges for the use of intellectual property, personal, cultural and recreational services, and government goods and services.It has a comparative advantage in manufacturing services on physical inputs owned by others, maintenance and repair services, construction services, telecommunications, computer and information services and other business services throughout the analysis period, and in transportation services only in 2020. When we evaluate according to the classification of Hinloopen and Marrewijk (2001), it is seen that China has a strong comparative advantage in manufacturing services on physical inputs owned by others in 2016 and 2017, among the services in which China has a comparative advantage, but in other years, strong comparative advantage in these services has been replaced by moderate comparative advantage.In construction services, while there was a moderate comparative advantage in 2016, it is noteworthy that China had a strong comparative advantage in other years. In other sectors where there is a comparative advantage, there is a weak comparative advantage.

Considering the classification of Hinloopen and Marrewijk (2001), India has a moderate comparative advantage in telecommunications, computer, and information services, and a weak comparative advantage in other business services. It is comparatively disadvantaged in 10 service sub-sectors other than these sectors. In other words, when India is compared to other group countries, it seems to be at a great disadvantage in the service sub-sectors.

For Russia, travel services, insurance and pension services, financial services, charges for the use of intellectual property, telecommunications, computer and information services, other business services (except 2016), and personal, cultural and recreational services are sectors where it is comparatively disadvantaged. It has a comparative advantage in manufacturing 
Dumrul, Y. \& Kılıçarslan, Z. (2022). BRICS Ülkelerinin Hizmet Ticaretinde Açıklanmış Karşılaştırmalı Üstünlükleri. Fiscaoeconomia, 6(1), 99-117. Doi: 10.25295/fsecon.1034136

services on physical inputs owned by others (except 2019 and 2020), maintenance and repair services, transport services, construction services, other business services (2016 only) and government goods and services. It is noteworthy that the degree of comparative advantage in construction services is strong. However, there is a moderate degree of comparative advantage in transport services among the sectors with a comparative advantage, and a weak comparative advantage in other sectors.

Industries where Brazil has a comparative disadvantage in all years are manufacturing services on physical inputs owned by others, maintenance and repair services (except 2018 and 2020), travel services, construction services, insurance and pension services, financial services,charges for theuse of intellectual property, telecommunications, computer and informatics services. However, Brazil has a weak comparative advantage in other business services (except 2020), moderate, personal, cultural and recreational services (except 2017 and 2018), and government goods and services.

South Africa has a moderare comparative advantage in travel services, and weak vis-à-vis the world in personal, cultural, and recreational services and government goods and services.It is comparatively disadvantaged in all years in manufacturing services on physical inputs owned by others, maintenance and repair services, transport services (except 2020), insurance and pension services, financial services, charges for the use of intellectual property, telecommunications, computer and information services and other business services.

It would be appropriate to determine an export policy to ensure sustainability in services with strong comparative advantage in BRICS countries and to increase the degree of comparative advantage in services with weak and moderate comparative advantage, and to support relevant sectors with incentives. This will contribute to the increase in the export revenues of the BRICS countries.In this study, the comparative advantage situation of the BRICS countries in the service sector was examined and the comparative advantage structure was shown with the data revealed by sub-sectors, and the reasons for the comparative advantage were not mentioned.In future studies, the reasons for comparative advantage in the service sector can be analyzed using different methodologies. 